\title{
LA EXPERIENCIA DE LA LIBERTAD: UN SALTO DE FE
}

\section{Martín ValdeZ}

Pontificia Universidad Católica del Perú

Resumen: El siguiente trabajo busca interpretar la paradoja de la fe presente en Temor y temblor a la luz de la problemática kantiana en torno a la libertad, de tal modo que podamos reconciliar el pensamiento de Kierkegaard con el racionalismo, pero al mismo tiempo, enriquecer a este último con un discurso de carácter existencial. Sostendremos que a la base de toda ética se encuentra una experiencia más allá de los límites de la razón, pero no por ello irracional.

Palabras clave: Kierkegaard, Kant, fe, libertad, racionalismo.

Abstract: This paper seeks to interpret Fear and Trembling's paradox of faith together with Kant's examination of the problem of freedom, in order to reconcile Kierkegaard's thought with rationalism, but at the same time, to enrich the latter with a more existential language. It argues that, at the ground of all ethics, a certain experience beyond the limits of reason is found, albeit not an irrational one.

Key words: Kierkegaard, Kant, faith, freedom, rationalism. 
Søren Kierkegaard escribió Temor y temblor a los 30 años, bajo el pseudónimo de Johannes de Silentio, haciendo referencia a lo que no puede ser dicho y es, por lo tanto, incomunicable. La obra gira alrededor de la historia de Abraham, en particular, al momento en que Dios le pide que sacrifique a su único hijo, Isaac. "Y quiso Dios probar a Abraham y le dijo: Toma a tu hijo, tu unigénito, a quien tanto amas, a Isaac, y ve con él al país de Moriah, y ofrécemelo ahí en holocausto sobre el monte que yo te indicaré” (Gn 22:I-2).

El argumento de Johannes de Silentio en Temor y temblor es relativamente simple: si es que no hay nada más elevado que la ética en este mundo, y tampoco nada inconmensurable en el hombre más allá de lo que posiblemente pueda expresar mediante su participación en ésta, entonces nunca existió la fe, precisamente porque siempre existió, y en consecuencia, Abraham está perdido. En efecto, si la fe está incluida en una ética universal accesible a todos, entonces nada sacamos de la historia de la relación particular entre Abraham con Dios.

Pero existe efectivamente algo por encima de lo ético (universal); esto es lo absoluto (Dios, en el ejemplo de Abraham). El particular, Abraham, entra en relación con lo absoluto, Dios, mediante la fe, de la siguiente forma:

"La fe consiste precisamente en la paradoja de que el particular se encuentra como tal particular por encima de lo universal, y justificado frente a ello, no como subordinado, sino como superior. Conviene hacer notar que es el particular quien después de haber estado subordinado a lo universal en su cualidad de particular llega a ser lo particular por medio de lo universal; y como tal, superior a éste, de modo que el particular como tal se encuentra en relación absoluta con lo absoluto. Esta situación no admite la mediación, pues toda mediación se produce siempre en virtud de lo universal; nos encontramos pues, y para siempre, con una paradoja por encima de los límites de la razón"342.

342 Kierkegaard, Søren, Temor y temblor, Madrid: Alianza Editorial, 200I, pp. II2-II3. He cambiado algunos términos siguiendo la versión en inglés: cf. Kierkegaard, Søren, Fear and Trembling. Repetition, Princeton: Princeton University Press, 1983, pp. 55-56. 
Leamos nuevamente con los personajes:

La fe consiste precisamente en la paradoja de que Abraham se encuentra como tal individuo por encima de la ética, y justificado frente a ella, no como subordinado, sino como superior. Conviene hacer notar que es Abraham quien después de haber estado subordinado a la ética en su cualidad de individuo llega a ser él mismo por medio de la ética; $y$ como tal, superior a ella, de modo que Abraham mismo se encuentra en relación religiosa con Dios. Esta situación no admite la mediación, pues toda mediación se produce siempre en virtud de lo universal; nos encontramos pues, y para siempre, con una paradoja por encima de los límites de la razón ${ }^{343}$.

La fe se presenta al entendimiento como una paradoja, cuya resolución se encuentra más allá del alcance de la razón humana. Expliquemos. En primer lugar, debemos diferenciar lo universal de lo absoluto, lo ético de lo religioso. Es cier to que ambas esferas pueden coincidir, pero en ese caso, y De Silentio es decisivo al respecto, la fe no sería necesaria, las categorías morales bastarían, y Abraham estaría perdido. Es gracias al ejemplo de Abraham, precisamente, que nos percatamos de que ambas esferas no siempre coinciden, que lo religioso se halla por encima. Un padre tiene un deber para con su hijo, y lo que se le exige a Abraham no sobrepasa este deber en el sentido ético; no se le ha pedido que actúe por un bien mayor, como podría ser el bienestar de un pueblo, tampoco hay una razón de por medio, como un Dios enfadado por algo que Abraham hizo. No hay, pues, forma de reconciliar la acción de Abraham con lo ético/universal. Simplemente se lo pidió y Abraham actuó porque creía, en virtud de lo absurdo, afirma De Silentio. $O$ es un asesino o es un creyente; o ha transgredido la ética, es un criminal más, un loco, un fanático, o la ha suspendido en virtud de algo más elevado; o lo uno o lo otro. No hay lugar para la mediación.

Desde un punto de vista menos lógico y más existencial, digamos, no hay que olvidar por un segundo que Abraham amaba a Isaac más que a nada en el mundo. Abraham (el particular) antepone su relación con Dios (lo absoluto) a su deber ético (lo universal, el amor del padre por el hijo), deber que no abandona sino que suspende, $y$ es en ese sentido que tenemos efectivamente 
una paradoja. Abraham no puede conciliar el amor que siente por su hijo con su deber hacia lo absoluto; al sacrificarlo, no lo deja de amar, justamente, lo ama más que nunca. Desde el punto de vista del espectador, todos observamos desde lo universal, pero el particular está solo en su relación con lo absoluto, puesto que sólo puede comunicarse y hacerse inteligible con otros en virtud de lo universal.

El particular no puede responder a nadie ni refugiarse en concepto alguno. Está solo en una experiencia incomunicable: el particular se encuentra aislado en ésta, es uno solo con su fe. Lo universal se suspende, pero mantiene su efecto sobre el particular. En una ética universalista el particular es el determinante último de su actuar, sí, puesto que es libre. Sin embargo, siempre puede encontrar refugio en saber que lo que hace está bien y en que otros seres racionales podrán comprenderlo. Cualquier ética universal siempre es radicalmente comunicativa. $Y$ es justamente la imposibilidad de la comunicación lo que aísla al particular en la paradoja de la fe, así: “(...) está en una soledad universal donde jamás se oye una voz humana, y camina solo, con su terrible responsabilidad a cuestas" 344 . El absurdo corresponde, así, al carácter incomunicable de la relación del particular con lo absoluto, cuando se coloca a sí mismo por encima de lo universal, como superior, pero sin abandonar el universal.

Ahora, icómo pueda ponerse el particular por encima de lo universal mediante el universal mismo? Es necesario que el individuo acoja al universal dentro de sí, en un actuar ético genuino $y$, a pesar de querer realizar este actuar ético más que nada, no lo haga, sino que en virtud del absurdo, a pesar de lo incomprensible de la situación y del mandato, renuncie a él. Sin embargo, de la misma forma que el particular renuncia al objeto que quiere (como Abraham renuncia a Isaac), lo recupera también en virtud del absurdo en este acto de fe. Pero, icómo funciona esto? ¿Puede el autor de Temor y temblor estar describiendo no otra cosa que un milagro, una retribución divina de nuestra lealtad sin sentido? Esto supone un problema. 
Lo que me propongo en este trabajo es rechazar cualquier tipo de interpretación fideísta de la paradoja de la fe. Puesto de otro modo, espero establecer que el carácter absurdo de la paradoja no refiere a algo irracional, sino al hecho, no poco importante, de encontrarse más allá de la comprensión humana. Para ello, recurriré en lo que queda al problema que supone la libertad humana tal como es abordado por Immanuel Kant en la tercera antinomia de la Crítica de la razón pura, para mostrar que incluso en la ética de este filósofo racionalista por excelencia hallamos una experiencia incomunicable e incomprensible, a la base de toda la moralidad, y que supone precisamente un acto de fe.

Lo que está en juego es la libertad; pero no la libertad entendida como la capacidad de elegir simplemente entre dos opciones, sino la libertad en tanto la capacidad humana de sobreponernos al mal, al pecado (dentro de la tradición cristiana), de respetar la dignidad humana en cada una de nuestras acciones, de desarrollar nuestro potencial al máximo dentro del contexto que nos ha tocado vivir. Esto es quizás lo más difícil que podemos concebir, significa una meta ideal, que nunca podremos estar seguros de haber alcanzado.

Pero, icómo es posible esta libertad, esta perfección? ¿No estamos acaso determinados por nuestra biología, la química, la física, nuestro entorno sociocultural? Cada proceso mental, cada decisión que tomamos tiene un correlato físico, a su vez sometido a leyes del mundo natural. Este es sin lugar a dudas el problema filosófico más incómodo. Hasta ahora no ha sido resuelto y quizás nunca lo sea.

Para superar el tercer conflicto de las ideas trascendentales de la antinomia de la razón pura, Kant introduce una figura de carácter inteligible, una idea que la razón postula, algo que podemos admitir como posible, como un supuesto, y de forma explícita, señala, "como una mera ficción"345. Este carácter opera en el mundo sensible sin alterar en lo más mínimo el orden de la naturaleza.

Toda la resolución de la tercera antinomia gira en torno a acomodar, mediante esta ficción de una causalidad meramente pensable, la libertad en un mundo sometido a leyes naturales. La libertad es algo que opera en la naturaleza con total realidad, pero sin alterar sus leyes. El argumento depende de un

345 Kant, Immanuel, Crítica de la razón pura, traducción de Mario Caimi, México D.F.: Fondo de Cultura Económica, 2009, p. 512 (A545/B573). 
fundamento suprasensible, mas no sobrenatural. Lo único que Kant quiere establecer en la tercera antinomia es la posibilidad de pensar una causalidad distinta a la de la naturaleza, sin que debilite esta última en lo más mínimo.

Pero hay que señalar que esta libertad trascendental, como la llama Kant, en tanto una causalidad inteligible, supone un uso ilegítimo de las categorías, si bien no está en conflicto con las leyes de la naturaleza. Que Kant se tome la libertad de forzar los límites de su filosofía crítica nos lleva a preguntarnos: ¿Por qué introducir "la ficción" de una causalidad de la razón pura y del mero pensamiento, que si bien no contradice los principios del entendimiento, no es legítimo respecto de ellos y posee cierta arbitrariedad?

Por supuesto que el interés de Kant apunta a resguardar la moralidad misma, que depende de, o equivale a, la ya mencionada concepción de una libertad positiva y perfecta. La ficción de un carácter inteligible no llega a ser completamente arbitraria, dado que corresponde precisamente a nuestra experiencia de la moralidad.

No podemos entender científicamente, ni siquiera filosóficamente, cómo la libertad opera en el mundo regido por leyes naturales, cómo la ldea se torna real. Pero la filosofía crítica pretende el silencioso mérito de haber mostrado que al menos podemos pensar la libertad sin contradicción con la naturaleza, si bien esto no demuestra en modo alguno que sea efectivamente real.

Y sin embargo, Kant afirma que "a veces encontramos, o al menos, creemos encontrar, que las ideas de la razón han mostrado efectivamente causalidad con respecto a las acciones del hombre" ${ }^{346}$. Más adelante, en la tercera Crítica, Kant va más allá y afirma que "entre todas las ideas de la razón, la libertad es la única idea cuyo objeto es un hecho" ${ }^{347}$. Si bien no entendemos cómo, Kant está seguro de que la libertad es algo real, que el actuar bajo la creencia en la libertad es inevitable. La ley moral es algo tan real como el cielo estrellado. "Yo veo el cielo estrellado y la ley moral ante mí”, exclama Kant, "y las relaciono inmediatamente con la consciencia de mi existir" ${ }^{348}$.

346 Ibid., p. 516 (A550/B578).

347 Kant, Immanuel, Crítica del discernimiento, traducción de Roberto R. Aramayo, Madrid: Alianza Editorial, 2012, p. 693.

348 Kant, Immanuel, Crítica de la razón práctica, traducción de Roberto R. Aramayo, Madrid: Alianza Editorial, 2000, p. 293. 
Para asegurar esta experiencia de la libertad es que Kant se ha preocupado de limitar el saber: no podemos mediar esta experiencia teóricamente bajo ningún concepto, es una práctica pura, racional, pero cuya posibilidad se encuentra siempre un paso más allá de la razón teórica. La fe consiste precisamente en creer y actuar de acuerdo a la libertad, y es en esta experiencia que cada particular se enfrenta cara a cara con lo absoluto, con aquello que está más allá de nuestra comprensión, absoluto al que, no obstante, le reconocemos la legitimidad de ser fuente de los principios que configurarán nuestra existencia.

En una moral universalista, nuestra libertad está sujeta a una ley moral. Podemos internalizar el deber, hacerlo nuestro, expresar el universal en cada momento, y justamente por eso, tenemos una libertad que nos asegura, que nunca nos abandona. Pero hay que creer que esa libertad $y$, por lo tanto, la moralidad misma, es efectivamente real, de modo que pueda determinar nuestro actuar y nuestras vidas. Hay, pues, un salto existencial, una creencia más allá de la razón, no por ello irracional, y en esto radica la experiencia de lo absurdo. Confrontarnos a aquello que no conocemos, más aún, que no podemos conocer, $y$, sin embargo, creer.

Pensemos en todos los sacrificios que nos demanda la virtud, la aniquilación del amor propio, todo lo terrenal que podríamos perder, y en algunas circunstancias, quizás la vida misma. La fe implica cierto movimiento de abandono, de renuncia, pero al mismo tiempo, la esperanza en que recuperaremos lo perdido, ya sea porque "Dios proveerá", en esta vida o en otra, o en todo caso, la esperanza o certeza de una dicha basada en nuestra dignidad y no en estímulos sensibles.

Pero entonces corremos el riesgo de ver el deber moral como algo negativo, siempre informándonos de algo que nos falta, de algo que no somos. Si nos quedamos en esta visión de lo ético, Nietzsche tendría razón en su genealogía: Dios, la demanda de perfección, la ley moral, sería efectivamente el invento más terrible del pensamiento, fuente de una culpa máxima. Pero la fe es precisamente la superación de estas consideraciones, es la afirmación de lo absoluto en uno mismo, es una práctica pura y genuinamente libre.

Hay sin lugar a dudas mucho de estético en el planteamiento de la paradoja 160 de la fe. No debemos aceptar jamás que la religión suspenda la ética. No se 
lo concederemos al autor de Temor y temblor. Pero perderíamos igualmente si pretendiésemos explicar el fenómeno de la ética de forma complemente científica, evolutiva, lógica e inclusive racional. Seguimos a Kant cuando señala, en las últimas líneas de la Fundamentación para una metafísica de las costumbres, que concebir el misterio que supone la existencia de la ley moral es lo máximo que puede pedírsele a una filosofía que aspira llegar hasta los confines de la razón humana. Kierkegaard estaría de acuerdo. 